\title{
Chapter 3 \\ Mortar and Pestle or Cooking Vessel? When Archaeology Makes Progress Through Failed Analogies
}

\author{
Rune Nyrup
}

\begin{abstract}
Most optimistic accounts of analogies in archaeology focus on cases where analogies lead to accurate or well-supported interpretations of the past. This chapter offers a complementary argument: analogies can also provide a valuable form of understanding of cultural and social phenomena when they fail, in the sense of either being shown inaccurate or the evidence being insufficient to determine their accuracy. This type of situation is illustrated through a case study involving the mortarium, a characteristic type of Roman pottery, and its relation to the so-called Romanization debate in Romano-British archaeology. I develop an account of comparative understanding, based on the idea that humans have a natural desire to understand ourselves comparatively, i.e., in terms of how we resemble and differ from societies at other times and places. Pursuing analogies can provide this type of understanding regardless of whether they turn out to be accurate. Furthermore, analogies can provide a similar form of understanding even when the evidence turns out to be insufficient to determine their accuracy.
\end{abstract}

Keywords Analogies · Optimism - Mortaria - Romanization debate - Comparative understanding $\cdot$ Value of understanding

\footnotetext{
R. Nyrup $(\bowtie)$

Department of History and Philosophy of Science and Leverhulme Centre for the Future of Intelligence, University of Cambridge, Cambridge, UK

e-mail: rn330@cam.ac.uk
} 


\subsection{Introduction}

Many archaeological interpretations are based on analogies with known societies. That is, they draw on comparisons with phenomena (artifacts, cultural practices, societal structures, etc.) that are already familiar, e.g., from anthropological studies, textual historical sources, other archaeological evidence or modern everyday experience. Nonetheless, archaeologists have often been uneasy about their reliance on analogies. In methodological debates, archaeologists have worried that analogies are unreliable or speculative, questioning whether the past is likely to resemble any familiar society - and if so, whether we would be able to tell. And to be sure, there are plenty of cases from the history of archaeology where apparently compelling analogy-based interpretations turned out to be deeply misleading. ${ }^{1}$

Philosophers and archaeologists who defend analogies have pushed back against this pessimistic view (e.g., Ascher 1961; Smith 1977; Salmon 1982; Wylie 2002; Currie 2016). By developing positive accounts of the criteria for good analogical inferences, they seek to counter pessimistic arguments through one or more of the following optimistic counterclaims. First, there are methodologically sound criteria by which archaeologists can recognize more plausible analogies. Second, even if past societies are unlikely to resemble present ones, analogies can still assist in generating accurate interpretations of the past. Third, archaeologists can (at least sometimes) obtain sufficient evidence to recognize an analogy-based interpretation as accurate.

While I find these arguments compelling, as far as they go, they do not in my view exhaust the case for pursuing analogies in archaeology. Most existing accounts focus on establishing the possibility of analogies succeeding, in the sense of leading to accurate and evidentially well-supported interpretations. Here, I want to propose a complementary line of justification, focusing on cases where analogies fail, in the sense that either the available analogies turn out to be inaccurate or the evidence turns out to be insufficient to determine whether they are accurate.

A justification of this kind would significantly strengthen the case for pursuing analogies in archaeology. Previous defenses of analogy show that wholesale pessimism is untenable. Nonetheless, it is not uncommon for archaeological inquiry to reach a stage where the available and foreseeable evidence only suffices to rule out some interpretations as inaccurate but not to establish any particular positive account as (most likely to be) accurate. In this chapter, I discuss a case study from RomanoBritish archaeology that illustrates this type of situation. The case study concerns a characteristic type of pottery called the mortarium, which became increasingly prevalent in Britain after the Roman conquest, and its relation to the so-called Romanization debate, i.e., the debate over how to best characterize the cultural changes that took place in regions conquered by the Romans. Analogies with other parts of the Roman world as well as more recent times are ubiquitous in these

${ }^{1}$ For discussion of such examples, see Ascher (1961, pp. 317-318), Orme (1981, ch 1) and Wylie (2002, pp. 137-38). 
debates. Yet there are few well-established conclusions regarding which of the interpretations suggested by these analogies are most likely to be accurate.

The aim of this chapter is to propose an account of how archaeology can achieve a significant form of progress through pursuing analogies even in cases like this. Specifically, I will argue (i) that we can gain an important form of understanding of cultural and social phenomena through analogies with already familiar societies, and (ii) that this is valuable to pursue in part because it supports a natural human desire to understand ourselves comparatively, that is, in terms of how our lives and societies resemble and differ from those at different times and places. Crucially, analogies can provide this form of understanding even (or especially) when they turn out to be inaccurate. Finally, I will argue (iii) that pursuing analogies produces a similar form of understanding even when what we learn is that the available evidence is insufficient to determine whether the analogies are accurate or not.

I begin with some preliminaries, explaining how I define 'analogy' and reviewing some extant accounts of analogy in archaeology (Sect. 3.2). Next, I introduce the mortarium case study (Sect. 3.3) and discuss the different ways analogies are used here (Sect. 3.4), including in what sense they count as 'failed'. I then move on to my positive account. I start by clarifying the type of account I seek to defend, through a comparison with Currie's (2018) defense of optimism about the historical sciences (Sect. 3.5). Finally, I develop my account in more detail (Sect. 3.6).

\subsection{Analogies, Analogical Reasoning, and Inferential Strategies}

I follow Hesse (1966) and Bartha (2010) in understanding an analogy to be a comparison between two systems that highlights: (a) respects in which they are known or assumed to be similar (the positive analogy), (b) dissimilar (the negative analogy), and (c) respects in which it is currently unknown to what extent they resemble each other (the neutral analogy). Analogical reasoning consists in drawing such comparisons in order to suggest the hypothesis that one or more features, already known or assumed to exist in one system (the source), also exist in the other (the target). This hypothesis may concern specific parts of the neutral analogy, or simply state that the target shares some (or many/most/...) of the source system's features (or some circumscribed subset of these), leaving it open exactly which.

The term 'suggest' here is intended to be neutral with regards to the epistemic force of the suggestion. Sometimes, the analogy is intended to provide some degree of evidence or epistemic justification for the hypothesis. However, analogies can also be used to merely suggest conjectures for further pursuit, without any commitment to their likeliness. Indeed (as I will argue), sometimes the point of pursuing analogy-based hypotheses is exactly to show them false. We will see examples of all of these uses of analogies below. 
What is the inferential structure of analogical reasoning? Under what conditions are we justified in going from the existence of a given analogy to the suggestion (with a given epistemic force) of further similarities? I do not suspect there to be any single account which adequately captures all instances of analogical reasoning as characterized above. Analogical reasoning draws and depends on our prior knowledge and assumptions about the two systems (Weitzenfeld 1984; Wylie 1988; Norton 2018). Depending on what kinds of background assumptions are available in a given context, there is likely to be several different inferential strategies available that rely on comparisons between two systems. Here, I will briefly review some commonly discussed inferential strategies for analogies in archaeology. ${ }^{2}$

The most straightforward strategy is to rely on background assumptions which make it likely that the source and target share relevant similarities. If I know that $A$ and $B$ are generally likely to be similar with regards to $F$-type features, and then learn that $A$ has a feature $F_{1}$, this would provide justification for the hypothesis that $B$ also has $F_{1}{ }^{3}$ Call this direct extrapolation. Many early defenses of analogies in archaeology (as summarized by Ascher 1961) relied on this strategy: they sought to identify general criteria for reliable analogical inferences, such as the source and target being temporally proximate or historically continuous, or the inferred features being technologically constrained. A perennial challenge for direct extrapolation is whether the similarity assumptions a given inference relies on are independent of the hypothesis one is aiming to support; as Grahame Clark puts it, there is a "real danger of setting up a vicious circle and assuming what one is trying to discover" (Clark 1951, p. 52, cited from Wylie 2002, p. 139). We will see this illustrated in the mortarium case study below.

The second inferential strategy, which I will call hypothesis-testing, is more indirect: first, a model, $M$, is developed based on our knowledge or assumptions about the source, describing the dependency relations between the features of the source. Second, $M$ is used, together with our knowledge or assumptions about the target, to infer what features we should and should not expect to find in the target domain, if $M$ also applied there. By checking whether these features can be found, we can test the hypothesis that $M$ also correctly describes the target. If this hypothesis is sufficiently confirmed, we can infer that the target also has any further features that play an essential role in $M$, even if these have not been directly observed. Hesse (1966) first proposed an account of analogical reasoning along these lines, since further elaborated by Bartha (2010). Similar accounts of analogies in archaeology have been defended by Smith (1977), Wylie (2002, ch 9) and Currie (2016). A significant challenge to this strategy concerns our ability to generate the right hypotheses. First, we can only test and confirm a hypothesis as accurate if we have generated the right

\footnotetext{
${ }^{2}$ For the sake of brevity, the following is kept fairly schematic. Nyrup (2020b) discusses these different uses of analogy in more detail and situates them within the history of debates in archaeology about analogy.

${ }^{3}$ This is an instance of what is sometimes known as 'direct inference' or 'statistical syllogism'. See Peden (2019) for a useful recent discussion of this type of inference and its relation to material theories of induction.
} 
hypothesis in the first place. Furthermore, even if we observe some set of features, $F$, predicted by the hypothesis that $M$ applies to the target, there may be another model that also predicts $F$ but otherwise differs significantly from $M$. As archaeologists have often pointed out, it can be difficult to rule out that such an alternative exists for something as variable and malleable as human social and cultural practices (Smith 1955; Freeman 1968; Gould 1980).

However, archaeologists can also use analogies to overcome, or at least ameliorate, these challenges to hypothesis-testing. The idea behind this strategy-advocated for example by Ucko and Rosenfeld (1967) — is to seek out as a broad and varied a range of potential analogies as possible in order to "widen the horizons of the interpreter" (Ucko 1969, p. 262), that is, to generate different models one might use to suggest potential interpretations of a given target. While analogies are not the only method for generating alternative hypotheses, and cannot be guaranteed to generate all possible alternatives, they nonetheless provide a fruitful method for broadening one's interpretative horizons (Wylie 1988; Currie 2018, ch 8).

Two variants of this use of analogies can be distinguished. In what I will call generation-for-confirmation, the underlying aim of generating interpretations is still to end up with a hypothesis that can be confirmed as true (or at least evidentially well-supported). For instance, Ucko and Rosenfeld claim that: "The more varied and the more numerous the analogies that can be adduced, the more likely one is to find a convincing interpretation for an archaeological fact" (1967, p. 157). The strategy suggested here is to first cast the net wide, in order to eventually whittle down the set of potential interpretations to a single plausible hypothesis (or at least, no more than a few), for instance through hypothesis-testing. Being able to rule out a wide and variable range of alternative hypotheses can be a powerful form of evidential reasoning (Reiss 2015; Nyrup 2020b, pp. 19-20). However, it of course requires that the alternative hypotheses can in fact be ruled out.

In the final strategy that I want to outline here, generation-as-criticism, using analogies to generate alternative interpretations instead serves a critical purpose. Rather than seeking to test (and ideally confirm) one of the hypotheses generated, their purpose is merely to highlight that there, in fact, exists plausible alternatives, hitherto unconceived, to some apparently well-confirmed interpretation. The reason for using analogies with known phenomena (rather than, e.g., fictional stories) is that this shows that these alternatives are more than mere logical or theoretical possibilities. Highlighting an alternative model which is already known to apply to a real case shows that the relations postulated by this model already exist (or existed) somewhere in the world, and thus represents a real possibility for other cases too, consistent with how human socio-cultural practices work in the actual world (as opposed to a mere logical or epistemic possibility). ${ }^{4}$

Compared to the other strategies, generation-as-criticism is the odd one out. Extant optimistic accounts of analogies in archaeology usually focus on cases where

\footnotetext{
${ }^{4}$ Bartha (2010) calls this modality 'prima facie plausibility' and defends an account of how analogies can provide this type of support, inspired by Whewell's and Herschel's concept of vera causa (Bartha 2010, pp. 302-304). See also Nyrup (2020a, pp. 7-11) for discussion.
} 
archaeologists succeed in using analogies to provide positive support for an interpretative hypothesis. Generation-as-criticism, by contrast, aims to throw doubt on some currently accepted interpretation. Perhaps for this reason, this use of analogies is rarely discussed by optimists. However, as the case study will illustrate, archaeologists do in fact often use analogies in this way. To be clear, my point here is not to disparage the other three inferential strategies. While I have highlighted some challenges faced by these strategies, I do not mean to suggest these uses of analogies are therefore untenable. As optimists have highlighted (e.g., Wylie 2002; Currie 2016), archaeologists can and do manage to overcome these challenges, often by combining several different inferential strategies. There is no general reason that analogies in archaeology cannot, in this sense, succeed. What I am interested in here, however, is what progress in archaeology looks like when this does not happen.

\subsection{The Mortarium and the Romanization Debate}

The mortarium is a characteristic type of pottery found across the Roman world (see Fig. 3.1), which can be described as a bowl or basin with a prominent rim, typically with a spout and embedded grits to create a rough inner surface (Tyers 1996, p. 116; Cramp et al. 2011, pp. 1339-1340). These characteristics, together with the fact that some mortaria sherds show signs of heavy wear, is often taken to suggest that its function was as grinding or mixing bowl. This interpretation is also supported by Roman sources describing their use for mixing and pounding ingredients (Cramp et al. 2011). Furthermore, as one archaeologist dryly notes, "Some of the vessels even helpfully have graffiti specifically stating that they are mixing bowls (pelves) or mortars (mortaria)" (Cool 2004, p. 30).

The mortarium is particularly interesting to archaeologists of Iron Age and Roman Britain, as it is rarely found on British sites from the (pre-Roman) Iron Age, but becomes increasingly common after the Roman conquest. In particular, mortaria

Fig. 3.1 Roman pottery mortarium. Reproducible under the Creative Commons AttributionShare Alike 3.0 Unported license. (Source: https:// upload.wikimedia.org/ wikipedia/commons/a/a8/ Roman_pottery_ mortarium.jpg)

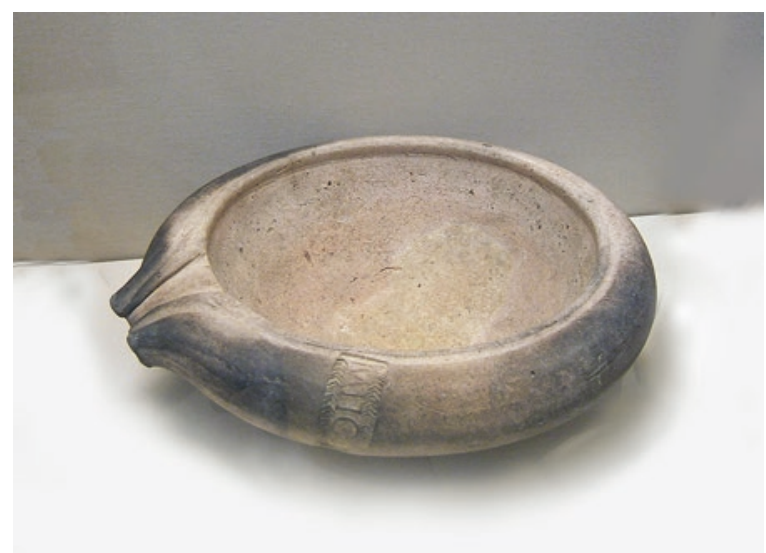


have been found not just in relation to military sites or urban centers, where they might be assumed to have been consumed by incoming soldiers and settlers, but from the later second century also on rural farmsteads (Cramp et al. 2011, p. 1340). In fact, in some areas, such as the Northwest of England, mortaria are significantly more common on rural sites than any other form of 'Roman' pottery (Peacock 2016, p. 24; cf. Evans 1995; Rush 1997; Cool 2004). Given its apparently well-understood function, the spread of mortaria in Roman Britain is sometimes interpreted as evidence of the pre-existing populations in Britain adopting more Roman ingredients or methods of cooking (Evans 1995; Tyers 1996, p. 116; cf. Cool 2006, p. 43). However, many archaeologists have argued for other possible uses, more continuous with pre-existing practices, including that it was used to grind or dehusk cereals (Phelps 1923), as a basin for curdling milk into cheese (Oswald 1943; Alcock 2001, p. 61), or simply as a convenient large bowl (Cool 2006, ch 6; Peacock 2016). We will look at some of the evidence for and against these interpretations below.

The question of how mortaria were used is significant due to its relation to the so-called Romanization debate. 'Romanization' is a name used for traditional accounts, developed in the early- to mid-twentieth century, of the changes brought about by the Roman conquest of Britain (and other provinces). These accounts construe such changes in terms of native populations 'becoming Roman' through a process of acculturation, by gradually adopting practices and conceptions more similar to the Mediterranean core of the Empire. Within this paradigm, the prevalence of 'Roman' material culture was usually seen as indicative of increased 'Romanization' (Ghisleni 2018, p. 139). Starting in the 1990s, the Romanization debate consisted of archaeologists extensively criticizing this approach. The Romanization model was seen to embody several problematic or overly simplistic assumptions, including among others (a) a reified, uniform conception of 'Roman culture', (b) a one-way transmission of ideas and practices to native populations, which (c) neglected or downplayed the role of these populations in shaping these changes.

While such assumptions were quickly rejected, the ongoing debate concerns what a more adequate framework might be, with archaeologists often drawing on post-colonial theory and analogies with more recent colonial experiences. For instance, Webster (2001) adapts the concept of 'creolization' from North American colonial archaeology, where it is used to describe processes in which slaves combined African and European cultural elements to create novel cultural forms-e.g., using European cooking utensils but African foodstuffs and cooking techniques. This is assumed to be often "a process of resistant adaption" (p. 218, original emphasis), where the resulting cultural blends cannot be understood independently of the unequal power relations under which they emerged. Similarly, Webster argues that Roman objects may have been used to "negotiate with, resist, or adapt Roman styles to indigenous ends" (p. 219), rather than signifying any aspiration to become Roman.

The Romanization debate is complex and ongoing. Other alternative frameworks have been proposed, centered around concepts such as 'imperialism', 'globalization' (or 'glocalization') and 'colonialism' (e.g., Ghisleni 2018; Versluys 2014; Pitts 
and Versluys 2015; Hingley 2011, 2015, 2017). I will not attempt to do justice to these here. What is interesting for my purposes is the role of analogies in some of these frameworks. Specifically, I will look at a few of the ways these questions play out in debates about the mortarium.

\subsection{Analogies and the Interpretation of Mortaria}

In this section, I highlight some of the ways analogies have been used in debates about the use and significance of mortaria in Roman Britain. My discussion is structured according to the inference strategies outlined in Sect. 3.2.

\subsubsection{Direct Extrapolation}

Some parts of the debate can be analyzed in terms of direct extrapolation. For instance, Cool (2006, p. 43) criticizes some discussions of the mortarium for simply assuming the function of mortaria to be food preparation, presumably in ways similar to those known from Roman sources. As mentioned above, several archaeologists have questioned this, emphasizing that this cannot be taken as given (e.g., Cool 2004 , p. 31, citing Reece 1988 , pp. 30-32). One way to understand this criticism is by viewing this assumption as resting on an implicit direct extrapolation from the Italian contexts described in the written sources to British contexts. What the critics are pointing out is that there is not sufficient background knowledge to license the assumption that these two contexts are likely to resemble each other in terms of how a given type of pottery was used.

To be sure, there are some contexts for which direct extrapolations of this type do seem well-supported. For instance, soldiers from the Mediterranean would plausibly have brought with them culinary practices from their home regions. Based on this assumption, we can infer that mortaria found at military forts occupied by such soldiers were likely used in ways similar to these Mediterranean regions. However, since the Romanization debate focuses on whether the existing population adapted similar practices, this type of assumption is not available: it would amount to assuming what the presence of mortaria was supposed to demonstrate.

\subsubsection{Hypothesis-Testing and Generation-for-Confirmation}

For this reason, most critical discussions of mortaria rely on other inferential strategies, such as hypothesis-testing and generation-for-confirmation. While not all hypotheses tested and generated are analogy-based, some of them are. Recall from Sect. 3.2 that, apart from serving as inspiration for the generation of hypotheses, 
analogies can play at least two further roles. First, through their knowledge of a given source, archaeologists can reason about the types of evidence we should expect if a mortarium was used analogously to that source (hypothesis-testing). Second, the case for a given interpretation can be strengthened through generating and providing evidence against prima facie plausible alternative interpretations (generation-for-confirmation).

One example is Oswald's (1943) arguments for the cheese-curdling hypothesis. Oswald discusses two analogies. First, he argues against the idea that mortaria were used analogously to a mortar and pestle, among other things by pointing out that the walls are too thin and breakable to be pounded with a pestle. ${ }^{5}$ Second, he considers another potential analogy, a similar-looking modern type of milk bowl used in Northern France and Savoy to curdle milk. Oswald suggests that the rough surface could have acted as a reservoir for curdling bacteria, while the spouts could have been used for draining off whey. Finally, he points out that since heating helps separate the whey from the curd, "it is noteworthy that many mortaria show signs of heat [i.e., sooting] on their exterior" (p. 46). The latter argument is an example of how background knowledge about the analogical source can be used to support hypothesis-testing. By drawing on his knowledge of the cheese-making process, Oswald is able to argue that the presence of sooting on mortaria sherds would be expected evidence if the cheese-curdling hypothesis were true.

Cool (2006, pp. 42-46) also discusses different potential analogies for the use of mortaria. First, she points out that mortaria are in fact unusually common in Britain compared to Italy (as an illustration, she cites an extensive exhibition of food-related objects from Pompeii which did not include mortaria). By highlighting the rarity of mortaria in the source of the analogy (Italy), she argues that the high prevalence of mortaria in Britain should be seen as evidence against them being used to produce 'Romanized' food (p. 45). Second, she points out that rural sites in first and second century Roman Britain also tend to have disproportionate amount of large glass bowls and samian ware bowls, leading her to suggest that "Perhaps on these sites mortaria were regarded simply as large bowls" (p. 45; Peacock 2016 suggests a similar interpretation for farmsteads in Cumbria).

Finally, under the heading of hypothesis-testing, it is also worth highlighting the residue analyses carried out by Cramp et al. (2011). In this study, researchers analyzed the nature of organic residues that had been absorbed into mortaria sherds, using methods such as gas chromatography and stable isotope analysis. They were able to obtain samples of sufficient quality from sherds from seven sites (six in Britain, one in Germany) and compared these to results from Roman and Iron Age cooking vessels. Thus, one of the hypotheses tested in this study is whether mortaria were used in a way analogous to these cooking vessels.

The study produced several interesting findings, including the following. First, while the mortaria and cooking vessels had contained or been used to process both

\footnotetext{
${ }^{5}$ Note, however, that this does not rule out mortaria being used to grind ingredients by hand or using a stone rubber (Alcock 2001, p. 69).
} 
plant- and animal-based products, plant-derived residues were detected with much higher frequency in mortaria compared to the cooking vessels. Second, most of the animal fats were from the carcass, although at one site, Stanwick (an agricultural village in Northamptonshire), several sherds contained residues from dairy fat. However, plant-based lipids were still more common, ruling out the hypothesis that the mortaria at Stanwick were used as single-purpose cheese-curdling bowls. Third, although mortaria show a higher proportion of plant-based fats, they contain the same types of residues as the cooking vessels. Finally, the frequency of components is comparable in Iron Age and Roman cooking vessels. For instance, both Iron Age and Roman cooking vessels from Stanwick also contain dairy fat residues, indicating some continuity in diet at this site. Overall, the authors conclude that the mortarium had some "unique role compared with other domestic vessels", different from any known metallic or ceramic Iron Age utensil, which "suggests a shift in cultural practice involving either new commodities, especially plants, or new apparatus or new recipes" (Cramp et al. 2011). However, they are unable to determine whether this role was for culinary or some other purpose, such as preparing cosmetics or pharmaceuticals.

While Cramp et al. thus provide evidence relevant to the function of mortaria, it should be noted that their study only looks at six British sites, four of which are either Roman forts, urban or high-status buildings (e.g., a villa). It is possible that mortaria played different functions for populations in other parts of Roman Britain.

\subsubsection{Generation-As-Criticism}

Finally, analogies have also been used, through the generation-as-criticism inferential strategy, to challenge interpretations of the significance or meaning of the cultural changes (if any) represented by the spread of the mortarium.

While it has not been applied directly to the mortarium case, the creolization framework can be seen as an example of this: the analogy to the material culture associated with African slaves in North America serves to generate an alternative account of the cultural changes in Britain during the Roman occupation. Assuming Cramp et al. are correct that the mortarium represents the introduction of new practices (at least in the contexts their samples came from), how should we interpret those changes? On a traditional Romanization account, these would be interpreted as the population adopting Roman culture, perhaps driven by an aspiration to become Roman. By contrast, the analogy with slaves in North America would suggest a different interpretation, where the changes are instead interpreted as resulting in a new cultural blend, distinct from both Roman and pre-existing culture, involving a more ambivalent or even resistant attitude to the cultural connotations of the mortarium.

A more recent example is Ghisleni's (2018) challenge to assumptions about what constitutes continuity and change in the Romanization debate. Drawing on work in the archaeology of colonialism, Ghisleni argues that earlier alternatives to the 
Romanization account, such as the creolization framework, still tend to presuppose a dichotomy between 'continuity' with pre-existing Iron Age culture vs. 'change', represented by Roman material culture. Even if we focus on more complex notions of cultural transformation beyond simply adopting Roman culture, this still "presupposes that we can recognize when something has been transformed" (p. 139). In Romano-British archaeology, Ghisleni argues, continuity tends to be defined statically by reference to how things were at the time of the Roman conquest, thereby "allying change with what is Roman or what appears to be a result of Roman occupation" (p. 142). This, however, ignores the fact that the culture of a given community is dynamic and itself continually evolving. Some changes may be natural extensions of previous practices; some forms of persistence may represent a break from previous trajectories (pp. 140-141).

Ghisleni cites several examples of these ideas from the archaeology of colonialism. One example is Silliman's $(2009,2010)$ discussion of European-produced pottery in colonial New England. Silliman criticizes the tendency to identify these unproblematically as 'European' items and as evidence of cultural change when found in Native American households (2010, p. 40): if used as part of daily life across generations, a given type of pottery may have been seen by people in these households as a part of their own life and history, rather than an external cultural influence. Even when found in British/Euro-American households, these often employed Native American servants who would have handled the items at least as often as their owner, making it problematic to interpret them as exclusively 'European'. Based on this observation, Silliman highlights different possible interpretations of how these servants might have viewed such items: perhaps they "cared nothing for the artifacts and resented their symbolic role in marking oppression, perhaps they handled them with care as part of their economic strategies for wellbeing, or perhaps they or their family members used the same kind of dishes in their own homes and felt some affinity for them" (Silliman 2010, p. 42).

Ghisleni applies this framework, among other things, to the interpretation of mortaria found near Durnovaria (a Roman town founded in Dorset around 65-70 CE), which were part of the sample studied by Cramp et al. (2011). Noting the evidence of changes in preparation techniques together with continuity in diet, Ghisleni argues:

As mortaria changed hands and uses in different contexts, as they were worked into practice through facilitating the consumption of familiar foods, and as they began to be manufactured in Britain, mortaria-as-introductions may not have always acted as a primary factor in the production of their social meanings. Glossing the category of mortarium as already and only a new object elides potential ambiguities of meaning (Ghisleni 2018, p 149)

As the above example involving European-produced pottery highlights, there are interpretative possibilities for the cultural identity and meaning of the mortarium, beyond those suggested by the Romanization and creolization accounts. Rather than seeing the mortarium and the associated changes in food preparation as a transformation of previous traditions, they may have been perceived as a natural continuation. The mortarium may not have represented cultural changes, adopted either 
aspiringly or resistantly, but they may instead have been associated with familiar foods or simply viewed indifferently.

\subsubsection{Summary: Success and Failure in the Interpretation of Mortaria}

In this section, I have highlighted some ways that analogies are used within the Romanization debate, focusing on interpretations of the function and cultural meaning of mortaria. As we have seen, analogies are used here to generate interpretative hypotheses, to reason about evidence for and against these, and to throw doubt on received interpretations. In one sense, we might see all of these as examples of analogies succeeding, insofar as they contribute to the inferential strategies within which they are employed. However, these 'successes' are of a different kind to the ones usually highlighted in optimistic accounts of analogy. Archaeologists have not so far been able to unambiguously confirm any comprehensive account of how mortaria were used in Roman Britain.

Regarding its use, some negative conclusions can plausibly be drawn. First, there seems good reason to doubt that mortaria in Britain generally played the same role as in Mediterranean regions. Second, some of the alternative hypotheses, such as them being single-purpose cheese curdling bowls, also seem doubtful, at least on the sites studied by Cramp et al. To the extent that any positive conclusions can be drawn, these are fairly vague-e.g., it "fulfilled a unique role compared with other domestic vessels ... whether this was for culinary or non-culinary (e.g., cosmetic or pharmaceutical) purposes" (Cramp et al. 2011, p. 1349) - and the evidence so far only comes from a limited range of sites.

Regarding its cultural meaning, the situation is even more ambiguous. While there is ample archaeological evidence that the Roman conquest brought about changes in Britain, for instance in terms of the types of pottery that was used, archaeologists have not reached any consensus on the significance or cultural meaning these might have held for different people living there. Instead, as illustrated by Ghisleni's arguments, the role analogies play in relation to these questions is often mainly to suggest new possible interpretations, not in order to confirm one of them as more likely, but rather to indicate a broader range of interpretative possibilities. Here, 'successful' uses of analogy neither involve confirming some interpretation as accurate nor to show it inaccurate, but rather to highlight how open these questions still are.

The current evidential situation may only be temporary. As I have emphasized, my aim is not to argue that these uncertainties are insurmountable. Further advances in techniques such as residue analysis might yield further evidence which, together with more detailed theoretical analyses, might allow archaeologists to narrow down the range of plausible interpretations of how mortaria were used or perceived in a given context. However, this cannot be guaranteed. In the remainder of this chapter 
I want to argue that even if the current situation proves to be persistent, this still represents a significant form of epistemic progress, worth achieving for its own sake.

\subsection{Optimism, Progress, and Pursuit Worthiness}

Adrian Currie (2018) energetically defends optimism about the historical sciences, including archaeology. Since his view bears some resemblances to the one I want to defend vis-à-vis analogies, it worth spelling out the differences between the two.

Currie defines optimism and pessimism as predictive stances concerning the probability that a given activity —in this case historical inquiry—will succeed: "The pessimist predicts that our attempts to reconstruct the past will often fail; the optimist predicts that we will often succeed" (p. 13). Currie emphasizes that success here should be construed in a broad, pluralistic sense. It does not just include discovering true or accurate theories, but also many other types of epistemic goods: "good explanations, adequate representations, precise predictions, new technologies, successful techniques, telling interventions, effective cures, and so forth" (p. 14). Furthermore, truth is not necessary for success: first, idealized models can sacrifice truth for the sake of producing better understanding; second, speculative hypotheses, even if they fail, are an important driver of progress in historical sciences, by generating 'scaffolds' and 'inferential tools' which can increase the epistemic reach of historical inquiry (Currie 2018, ch 10-12).

In some ways, this aligns with my view: I want to provide an argument for optimism about the use of analogies in archaeology that goes beyond them suggesting true or well-established interpretations. However, Currie's optimistic arguments still give more prominence to truth or truth-related notions than what I am after here. First, while idealizations involve falsehoods, they are usually still assumed to 'get things right' in some ways - i.e., have some truth-content-in virtue of which they generate understanding. Second, Currie's account of how failed speculative hypotheses drive progress rely on them providing resources for further stages of inquiry to generate knowledge. By contrast, I want to argue that analogy-based hypotheses can also provide an important form of understanding in virtue of them being rejected as false or simply shown to be less certain than previously thought.

A way to further elucidate the differences between Currie's view and mine is by considering how each justifies the pursuit of analogy-based hypotheses. Optimism is closely related to pursuit worthiness: the likelier we think an activity is to succeed, the more reason we have to invest time and resources in pursuing it. Expected utility models, along the lines of Nyrup (2015, 2017, ch 2), provide a useful framework for analyzing notions of pursuit worthiness.

In general, these models are constructed by distinguishing a set of states of the world, $\left\{s_{l}, \ldots, s_{n}\right\}$, and a set of epistemic states, $\left\{e_{1}, \ldots, e_{m}\right\}$. Each pair of these represent a distinct epistemic outcome. For instance, in a simple model, focused on a single hypothesis $h$, we might distinguish two states of the world, $\{h, \neg h\}$, representing $h$ being either true or false, and three epistemic states, $\left\{\operatorname{acc}_{h}, \operatorname{rej}_{h}, \operatorname{sus}_{h}\right\}$, 
representing either that we accept, reject or suspend judgement on $h$. This results in six possible epistemic outcomes (accepting a truth, rejecting a truth, accepting a falsehood, suspending judgement, etc.). For each epistemic outcome, there will be a utility, $\mathrm{u}\left(e_{j}, s_{i}\right)$, representing how valuable achieving that outcome would be, and a probability, $\operatorname{Pr}\left(e_{j}, s_{i} \mid a\right)=\operatorname{Pr}\left(s_{i}\right) \times \operatorname{Pr}\left(e_{j} \mid s_{i}, a\right)$, that pursuing an activity $a$ will result in that outcome. The pursuit worthiness of the activity $a$ can then be modelled as the expected utility given by:

$$
\mathrm{EU}(a)=\sum_{i} \operatorname{Pr}\left(s_{i}\right) \times \sum_{j}\left(\operatorname{Pr}\left(e_{j} \mid s_{i}, a\right) \times \mathrm{u}\left(e_{j}, s_{i}\right)\right)
$$

For instance, in the simple model, $\mathrm{u}\left(\mathrm{acc}_{h}, h\right)$ is the utility of a true positive, $\operatorname{Pr}\left(\operatorname{acc}_{h} \mid h, a\right)$ is the probability that pursing $a$ will correctly determine that $h$ is true, and so on.

Within this framework, there are two obvious ways to argue for the pursuit worthiness of some activity. One can either show that the probability of achieving some positive epistemic outcome (or avoiding some negative epistemic outcome) is higher than previously thought; or one can argue that the utility of some epistemic outcome is higher than previously thought.

Typically, optimists about analogies in archaeology have focused on probabilities: they argue that pursuing analogies is more likely to result in us learning the truth of some hypothesis than pessimists assume. In terms of the formal model, if $p_{\text {analog }}$ denotes the activity of pursuing analogies, traditional optimists argue for higher values for probabilities of the form $\operatorname{Pr}\left(\operatorname{acc}_{h} \mid h, p_{\text {analog }}\right)$ or $\operatorname{Pr}\left(\operatorname{rej}_{h} \mid \neg h, p_{\text {analog }}\right)$. As long as $\mathrm{u}\left(\operatorname{acc}_{h}, h\right)>0$ and $\mathrm{u}\left(\operatorname{rej}_{h}, \neg h\right)>0$, i.e., true positives and true negatives have some positive value, this increases $\operatorname{EU}\left(p_{\text {analog }}\right)$.

Currie's optimist view augments this in two ways. First, the argument from idealization points out that there are some epistemic outcomes that involve accepting a strictly speaking false hypothesis, but nonetheless produces a valuable form of understanding. Thus, some utilities of the form $\mathrm{u}\left(\mathrm{acc}_{h} \mid \neg h\right)$ are higher than pessimists assume. Second, the argument from scaffolding highlights that for some hypotheses, the epistemic outcome of rejecting a falsehood can still have an indirect value, by increasing the probability of determining the truth of other hypotheses.

Like the argument from idealization, my account also focuses on raising utilities, but instead targets the utilities, $\mathrm{u}\left(\mathrm{rej}_{h}, \neg h\right), \mathrm{u}\left(\operatorname{sus}_{h}, h\right)$ and $\mathrm{u}\left(\operatorname{sus}_{h}, \neg h\right)$, of rejecting false analogy-based hypotheses or suspending judgement. Furthermore, unlike Currie's argument from scaffolding, I want to argue that these epistemic outcomes (at least sometimes) have higher value in a more direct sense, in that their value can be realized even in the absence of any further archaeological inquiry. ${ }^{6}$

\footnotetext{
${ }^{6}$ As will become clear below, realizing the value of this epistemic outcome may still require further reasoning of some sort. Thus, the distinction here is not strictly speaking between extrinsic and intrinsic value.
} 


\subsection{Making Progress Through Failed Analogies}

In this section, I outline a positive account of the value of failed analogies. ${ }^{7}$ It proceeds in three steps. First, I argue that one important epistemic good produced by archaeology is comparative understanding - that is, understanding of how social and cultural practices at different times and places resemble and differ from each other-and that analogies are well-suited for producing this type of understanding. Second, I propose an account of why this type of understanding seems particularly valuable in archaeology. Finally, I argue that this account also provides an account of the value of learning how ambiguous and uncertain the answers to some of these questions are.

\subsubsection{Comparative Understanding}

Many of the questions archaeologists seek to address are comparative. We are not just interested in understanding what life was like for people living on farmsteads in Roman Britain, but also how similar or different this was to life at Roman forts and, in turn, how this compared, say, to life in Italian cities. Understanding the Roman world involves, not just understanding the different times and places that it comprised in isolation, but also patterns of similarity and difference between these. Pushing this argument further, we are not just interested in understanding the Roman world in isolation either. We, including many archaeologists, also naturally wonder how the Roman conquest of Britain compares to other imperial projects, both contemporaneous (e.g., Imperial China) and more contemporary (e.g., the British Empire). Thus, one important epistemic good that archaeology seeks to produce is understanding of social and cultural similarities and differences across different times and places, including our own. ${ }^{8}$

Recall from Sect. 3.2 that I define analogies as comparisons of similarities and differences between two systems. Given this definition, it should be obvious why the pursuit of analogies in archaeology is an effective strategy for producing comparative understanding: it consists exactly in a comparison of the similarities and differences between social and cultural practices (or materials relating to these) at different times and places. Notice that this also accounts for why we are interested in analogies with societies that do or did actually exist, as opposed to analogies with merely hypothetical or fictional societies. Counterfactual history notwithstanding,

\footnotetext{
${ }^{7}$ The argument in this section develops and expands on remarks made in Nyrup (2020b, pp. 22-23, pp. 28-29).

${ }^{8}$ In a paper arguing that archaeology can and should be relevant to anthropology, Binford (1962) expressed this idea thus: "it must be asked, 'What are the aims of anthropology?' Most will agree that the integrated field is striving to explicate and explain the total range of physical and cultural similarities and differences characteristic of the entire spatial-temporal span of man's existence" (p. 217, original emphasis).
} 
the type of comparative questions I have highlighted above concern similarities and differences across actual time and space.

Crucially, analogies are conducive to addressing questions of both similarities and differences. While analogical reasoning, on my definition, consists in suggesting further similarities between the source and the target, rejecting such a hypothesis amounts to accepting the hypothesis that they have certain differences. Thus, rejecting a false analogy-based hypothesis directly provides a significant epistemic good, worth pursuing for its own sake.

\subsubsection{The Value of Comparative Understanding in Archaeology}

In the argument just given, I relied on the intuitive idea that many significant questions in archaeology concern similarities and differences between societies. Why is it valuable to answer such questions?

Notice first that the above observations do not translate straightforwardly to the natural sciences. It is arguably valuable in physics to discover positive analogiessay, between atoms and the solar system or liquid drops and the atomic nucleus. ${ }^{9}$ However, it is not obvious that negative analogies are significant in the same way. To be sure, the discovery that the atom is importantly different from a solar system was indirectly valuable, since it allowed physicists to develop more adequate models of the atom. But learning about such dissimilarities does not, in and of itself, seem a particularly significant discovery. In most cases, learning about differencese.g., that the atom differs from a gyroscope, from a biomolecule or from a crystal lattice-seems of limited value.

By contrast, learning that the mortarium played a different role in Britain than in other parts of the Roman world does seem an interesting archaeological discovery, even if we do not have a positive account of what that role was. Similarly, when it comes to analogies with our own time, learning how the past differs from the present seems at least as valuable as learning of similarities: often, the value of learning about archaeology is an appreciation of how different life in the past would have been from our own. It is this phenomenon I want to provide an account of; when we are concerned with human beings, and thus ultimately ourselves, understanding differences seems to be particularly significant. ${ }^{10}$

My starting point will be the account of the value of historical understanding recently proposed by Grimm (2017). Grimm argues that there is no deep difference in the 'epistemic profile' of understanding produced by natural science and history: in both cases, understanding consists in grasping how different parts of a system

\footnotetext{
${ }^{9}$ See Nyrup (2020a) for further discussion of different accounts of the value of positive analogies in physics.

${ }^{10}$ I do not mean to suggest that understanding differences cannot also be significant in other scientific domains. The account I propose here is specific to the human and social sciences, but is compatible with understanding differences being valuable for other reasons as well.
} 
relate to and depend on each other. For instance, he rejects the idea that things such as narrative understanding or holistic understanding of context are absent from the natural sciences. Rather, he argues that what makes historical understanding distinctive is the extrinsic benefits that come from understanding human affairs, namely that it puts us in a better position to understand how to live well, which we do not get in the same way from an understanding of non-human natural phenomena.

Specifically, Grimm argues that historical understanding can help us achieve two kinds of benefits. First, it can help us evaluate the legitimacy of our current institutions by better understanding how and why they were created in the first place. For instance, if we discover that the creation of a given institution was driven by "darker forces such as power, or oppression, or privilege, this gives us a powerful lens through which we can assess our practices not just as rational or irrational, but as just or unjust, as oppressive or discriminatory, and so on" (p. 20). Second, historical understanding can give us a better sense of the different possible ways of being human, thereby offering us "different, and perhaps in some ways superior, models for living well" (p. 21). Grimm gives one concrete example of this: learning more about what goods were regarded as important at other times can help us either to realize that "our own ordering of goods might be misguided or in some ways stunted" (p. 21) or to "appreciate the merit of our own arrangement of goods, insofar as we come to think that a prior society was lacking in various ways" (p. 21, fn. 34).

The second of these, that learning about life in the past gives us new models for how to live well, provides a straightforward account of the value of understanding differences between human groups, and thus of the value of rejecting analogies. Take comparisons between the past and present first: obviously, it is by learning how a past society differs from our own, as opposed to how they resemble each other, that we can obtain a new model. Second, once we have an understanding of the similarities and differences between our own life and life in a given past society, learning about differences between this society and other past societies can provide us with further models, without having to draw analogies directly with the present.

However, the first of the benefits proposed by Grimm is also relevant. While our current institutions are not themselves directly descended from the Roman state, archaeologists and historians have highlighted that many of the concepts we use to understand and justify existing social arrangements-e.g., 'empire', 'civilization', 'just war' - have emerged from Roman concepts and been shaped by the reception of these through various points in history (e.g., Morley 2010; Hingley 2011). Better understanding the genealogy of these concepts can thus help us better evaluate these social arrangements. Furthermore, social institutions or cultural practices are often articulated and justified based directly on analogies with the past. For instance, as Morley (2010, pp. 1-13) details, analogies with the Roman Empire have variously been invoked to justify imperialism ("British rule in India [was described as] 'an Empire similar to that of Rome, in which we hold the position not merely of a ruling but of an educating and civilizing race", p. 3), to criticize current policies ("the Romans' tolerance of diversity among their subjects [was contrasted] with the actions of the French in Algeria", p. 3), and occasionally to outright denounce institutions (e.g., comparisons between the European Union and the Roman Empire, p. 8). 
While Morley focuses on Empire, this points to a more general phenomenon. Whether for better or worse, humans have a natural tendency to understand our social and cultural practices comparatively. We appreciate and evaluate these, at least in part, based on how they compare with other individuals or societies, highlighting similarities with those we admire and distinguishing them from those we despise. In a culture that admires the Romans, highlighting ways in which a set of institutions resemble those of the Romans will often lend them some legitimacy. Conversely, highlighting the role violent repression played in the Roman occupation may lead us to reassess other colonialist projects (Hingley 2017, p. 90). ${ }^{11}$ In all of these cases, comparisons with the Romans provide more than just an abstract model, describing one possible way of organizing a given set of social and cultural practices. Rather, the analogies play a more direct role in determining their value and legitimacy.

It would go beyond the scope of this chapter to give a more detailed account of this type of moral reasoning. ${ }^{12}$ For present purposes, it is sufficient that it constitutes one significant way that analogies are used to make decisions about how to live well. Since both positive and negative analogies are relevant to this usage, this provides an additional account of the value of pursuing analogies in archaeology.

\subsubsection{The Value of Uncertainty}

So far, I have argued that pursuing analogies in archaeology can provide a valuable form of understanding, regardless of whether the result is to accept or reject analogybased hypotheses. The final step of my argument is that even when the result is an increased uncertainty about which hypothesis (if any) is most accurate, this still represents a worthwhile form of progress.

My account builds on certain methodological ideas which have recently been defended within Roman history and archaeology by Morley (2010) and Hingley (e.g., 2011, 2015, 2017).

Having highlighted how analogies with the Roman Empire have been used politically, Morley (2010) goes on to point out that these analogies usually assume an unproblematic knowledge of what the Roman Empire was like. However, he notes:

\footnotetext{
${ }^{11}$ Furthermore, the inferences can run in both directions: the role of many of the analogies invoked within the Romanization debate is to highlight interpretative possibilities according to which Roman cultural influence in Britain was less benign than otherwise supposed. This may in turn inform our assessment of more recent forms of cultural colonialism (Hingley 2017, pp. 99-102, p. 106).

${ }^{12}$ E.g., on the one hand, some instances of this type of reasoning may seem little more than ascribing guilt by association. On other hand, it is usually taken to be an axiom of moral reasoning that cases should be treated alike unless some morally relevant difference can be identified. How to tell apart legitimate and fallacious uses of this type of moral reasoning is not a question I will try to answer here.
} 
Our actual knowledge of Rome is fragmentary and sometimes contradictory ... the labor of scholars since the eighteenth century has tended to multiply uncertainties rather than establish certainties as growing understanding of the way modern societies work has highlighted our ignorance about the operations of Roman society (Morley 2010, p. 9)

In my terminology, what Morley describes is modern analogies being used within the generation-as-criticism strategy to highlight our uncertainty about the Roman world. This is a valuable contribution, since the political uses of Roman analogies draw their strength from the reality of the (supposed) historical facts they cite. As Morley puts it:

This is one reason why the Roman Empire is worth studying: not as a means of understanding better how to run an empire and dominate other countries, or of finding a justification for humanitarian or military intervention, but as a means of understanding and questioning modern conceptions of empire and imperialism, and the way they are deployed in contemporary political debates (Morley 2010, p. 10)

Hingley defends a more general argument. Building on observations such as Morley's, he argues that studies of the ancient world are inevitably intertwined with contemporary political ideas and concerns. Because of the "highly fragmentary nature of our understanding of the Roman Empire" (2011, p. 105), it is necessary to draw on contemporary ideas and concepts to "interpret the empire" (p. 105) and "give meaning to the past" (p. 109). He criticizes approaches to classical studies based on avoiding all modern concepts in favor of "immersing oneself in classical texts" (p. 104). Far from avoiding anachronism, the result is rather that "ideas are reproduced in an anachronistic manner, often without any form of conscious acknowledgement" (p. 104). Instead, Hingley advocates a methodological approach where the influence of contemporary ideas and political concerns on archaeological interpretation are explicitly acknowledged and studied. His point is not to undermine or reject all such interpretations, but rather to understand them better in order to ensure that they "will not be misinterpreted, or even misused" (p. 112). ${ }^{13}$

Building on these ideas, then, my argument is this: on the account given above, confirming and rejecting analogies is valuable in part because it helps us understand social arrangements comparatively, in terms of how they compare to societies at other times and places, thereby helping us understand how to live well. However, doing this successfully requires that we are able to correctly accept and reject such analogies. Re-evaluating our attitude, say, towards cultural transformation brought about by colonialism based on a mistaken analogy with the Romans is not valuable; we want comparative understanding that is based on how things actually were. Thus, getting a clearer understanding of the uncertainties and ambiguities in our understanding of the past in itself contributes to our ability to live well. It helps us better understand our epistemic relationship to the past, thereby enabling us to better evaluate analogy-based reasons for or against the legitimacy and value of current

\footnotetext{
${ }^{13}$ Cf. Hingley (2017, p. 105): "one of the main purposes of this field of study is to enable archaeologists to continue to focus critical attention on the entanglement of the past and the present and to ensure that powerful classical concepts are not used simplistically to justify modern political and military actions".
} 
social and cultural practices. Furthermore, as we saw above, analogies deployed in service of the generation-as-criticism strategy can play a crucial role in helping us obtain this type of understanding.

To be clear, this type of archaeological meta-understanding (i.e., understanding of the uncertainties and ambiguities in our first-order understanding of the past) is only valuable if it is itself accurate. While I follow Gero (2007) in arguing that archaeologists should 'honor' the uncertainties inherent in their interpretations, only those uncertainties which actually exist are worth honoring. Spuriously creating unnecessary ambiguity or abandoning any attempt to determine which interpretations are most plausible in light of the available evidence is as at least as problematic as uncritically ignoring or glossing uncertainty.

\subsection{Conclusion}

In this chapter, I have used debates about the use and cultural significance of the mortarium, and its relation to the Romanization debate more generally, to provide a broader view of the reasons for using analogies in archaeology. Firstly, there are several different inferential strategies in the service of which analogies can be deployed, including what I have called direct extrapolation, hypothesis-testing, generation-for-confirmation, and generation-as-criticism. All four strategies are illustrated in the mortarium case study. Since the purpose and challenges of each of these differ, the justification and adequacy criteria for using them will differ as well (cf. Nyrup 2020b). Secondly, I have highlighted that the result of archaeological inquiry is often to give us a deeper understanding of the uncertainties and ambiguities we face when trying to understand the past, and that analogies-in particular when used for the purpose of generation-as-criticism - can play a key role in securing this. In this way, archaeology can make progress even through failed analogies.

My account of the value of failed analogies is to a certain extent explorative; it still contains a number of loose ends which will need to be tied up. In particular, I have relied on some intuitive ideas about the comparative nature of our understanding of human phenomena in the past and about the role of analogies in helping us to understand how to live well. Further exploring the nature and value of archaeological understanding will be crucial to obtaining a broader and richer account of the reasons to be optimistic about archaeological inquiry.

Acknowledgements I'm grateful to Jennifer Peacock for helping me come to grips with mortaria and the Romanization debate. This work was supported by the Wellcome Trust [213660/Z/18/Z] and the Leverhulme Trust through the Leverhulme Centre for the Future of Intelligence [RC-2015-067]. 


\section{References}

Alcock JP (2001) Food in Roman Britain. Tempus, Stroud

Ascher R (1961) Analogy in archaeological interpretation. Southwestern J Archaeol 17:317-325

Bartha P (2010) By parallel reasoning: the construction and evaluation of analogical arguments. Oxford University Press, New York

Binford L (1962) Archaeology as anthropology. Am Antiq 28:217-225

Clark JG (1951) Folk-culture and the study of European prehistory. In: Grimes EF (ed) Aspects of archaeology in Britain and beyond. HW Edwards, London, pp 49-65

Cool HEM (2004) Some notes on spoons and mortaria. In: Croxford B, Eckardt H, Meade J, Weekes J (eds) TRAC 2003: proceedings of the thirteenth annual theoretical Roman archaeology conference, Leicester 2003. Oxbow Books, Oxford

Cool HEM (2006) Eating and drinking in Roman Britain. Cambridge University Press, Cambridge

Cramp LJE, Evershed RP, Eckhardt H (2011) What was a mortarium used for? organic residues and cultural change in Iron Age and Roman Britain. Antiquity 85:1339-1352

Currie A (2016) Ethnographic analogy, the comparative method and archaeological special pleading. Stud Hist Phil Sci 55:84-94

Currie A (2018) Rock, bone and ruin: an optimist's guide to the historical sciences. MIT Press, Cambridge, MA

Evans J (1995) Later Iron Age and 'native' pottery in the north-east. In: Vyner B (ed) Moorland monuments: studies in the archaeology of north-east Yorkshire in honour of Raymond Hayes and Don Spratt (CBA research report 101). Council for British Archaeology, York, pp 46-68

Freeman LG (1968) A theoretical framework for interpreting archaeological materials. In: Lee RB, DeVore I (eds) Man the hunter. Aldine, Chicago, pp 262-267

Gero J (2007) Honoring ambiguity/problematizing certitude. J Archaeol Method Theory 14:311-327

Ghisleni L (2018) Contingent persistence: continuity, change, and identity in the Romanization debate. Curr Anthropol 59:138-166

Gould R (1980) Living archaeology. Cambridge University Press, Cambridge

Grimm SR (2017) Why study history? On its epistemic benefits and its relation to the sciences. Philosophy 92:399-420

Hesse M (1966) Models and analogies in science. University of Notre Dame Press, Notre Dame

Hingley R (2011) Globalization and the Roman empire: the genealogy of 'empire'. SEMATA: Ciencias Sociais e Humanidades 23:99-113

Hingley R (2015) Post-colonial and global Rome: the genealogy of Empire. In: Pitts M, Versluys MJ (eds) Globalisation and the Roman world: world history, connectivity and material culture. Cambridge University Press, Cambridge, pp 32-46

Hingley R (2017) The Romans in Britain: colonization on an imperial frontier. In: Beule CD (ed) Frontiers of colonization. University of Florida Press, Gainesville, FL, pp 89-109

Morley N (2010) The Roman Empire: roots of imperialism. Pluto Books, New York

Norton J (2018) Analogy. https://www.pitt.edu/ jdnorton/papers/material_theory/4.\%20Analogy. pdf. Accessed 25 June 2020

Nyrup R (2015) How explanatory reasoning justifies pursuit: a Peircean view of IBE. Philos Sci 82:749-760

Nyrup R (2017) Hypothesis generation and pursuit in scientific reasoning. Doctoral thesis, Durham University. http://etheses.dur.ac.uk/12200/

Nyrup R (2020a) Of water drops and atomic nuclei: analogies and pursuit worthiness in science. Br J Philos Sci 71(3):881-993. https://doi.org/10.1093/bjps/axy036

Nyrup R (2020b) Three uses of analogy: a philosophical view of the archaeologist's toolbox. In: Marila M, Ahola M, Mannermaa K, Lavento M (eds) Interarchaeologia 6: archaeology and analogy. University of Helsinki, Helsinki

Orme B (1981) Anthropology for archaeologists: an introduction. Ducksworth, London 
Oswald F (1943) The mortaria of Margidunum and their development from AD 50 to 400. Antiqu J 22:45-63

Peacock J (2016) When is a mortarium not a mortarium? analogies and interpretation in Roman Cumbria. In: Erskine G, Jacobsson P, Stetkiewicz S (eds) Proceedings of the 17th Iron Age research student symposium. Archaeopress, Oxford, pp 20-27

Peden W (2019) Direct inference in the material theory of induction. Philos Sci 86:672-695

Phelps JJ (1923) The culinary use of mortaria. Trans Lancashire Cheshire Antiq Soc 39:1-15

Pitts M, Versluys MJ (2015) Globalisation and the Roman world: perspectives and opportunities. In: Pitts M, Versluys MJ (eds) Globalisation and the Roman world: world history, connectivity and material culture. Cambridge University Press, Cambridge, pp 3-31

Reece R (1988) My Roman Britain. Cotswold Studies, Cirencester

Reiss J (2015) A pragmatist theory of evidence. Philos Sci 82:341-362

Rush P (1997) Symbols, pottery and trade. In: Meadows K, Lemke C, Heron J (eds) TRAC 96: proceedings of the sixth annual theoretical Roman archaeology conference. Oxbow Books, Oxford, pp 55-64

Salmon M (1982) Philosophy and archaeology. Academic, New York

Silliman SW (2009) Change and continuity, practice and memory: native American persistence in colonial New England. Am Antiq 74:211-230

Silliman SW (2010) Indigenous traces in colonial spaces: archaeologies of ambiguity, origin, and practice. J Soc Archaeol 10:28-58

Smith B (1977) Archaeological inference and inductive confirmation. Am Anthropol 79:598-617

Smith MA (1955) The limitations of inference in archaeology. Archaeol Newsl 6:3-7

Tyers P (1996) Roman pottery in Britain. Routledge, London

Ucko P (1969) Ethnography and archaeological interpretation of funerary remains. World Archaeol $1: 262-280$

Ucko P, Rosenfeld A (1967) Paleolithic cave art. World University Library, London

Versluys MJ (2014) Understanding objects in motion: an archaeological dialogue on Romanization. Archaeol Dialog 21:1-20

Webster J (2001) Creolizing the Roman provinces. Am J Archaeol 105:209-225

Weitzenfeld JS (1984) Valid reasoning by analogy. Philos Sci 51:137-149

Wylie A (1988) 'Simple' analogy and the role of relevance assumptions: implications of archaeological practice. Int Stud Philos Sci 2:134-150

Wylie A (2002) Thinking from things: essays in the philosophy of archaeology. University of California Press, Berkeley

Open Access This chapter is licensed under the terms of the Creative Commons Attribution 4.0 International License (http://creativecommons.org/licenses/by/4.0/), which permits use, sharing, adaptation, distribution and reproduction in any medium or format, as long as you give appropriate credit to the original author(s) and the source, provide a link to the Creative Commons license and indicate if changes were made.

The images or other third party material in this chapter are included in the chapter's Creative Commons license, unless indicated otherwise in a credit line to the material. If material is not included in the chapter's Creative Commons license and your intended use is not permitted by statutory regulation or exceeds the permitted use, you will need to obtain permission directly from the copyright holder.

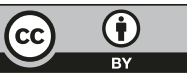

